
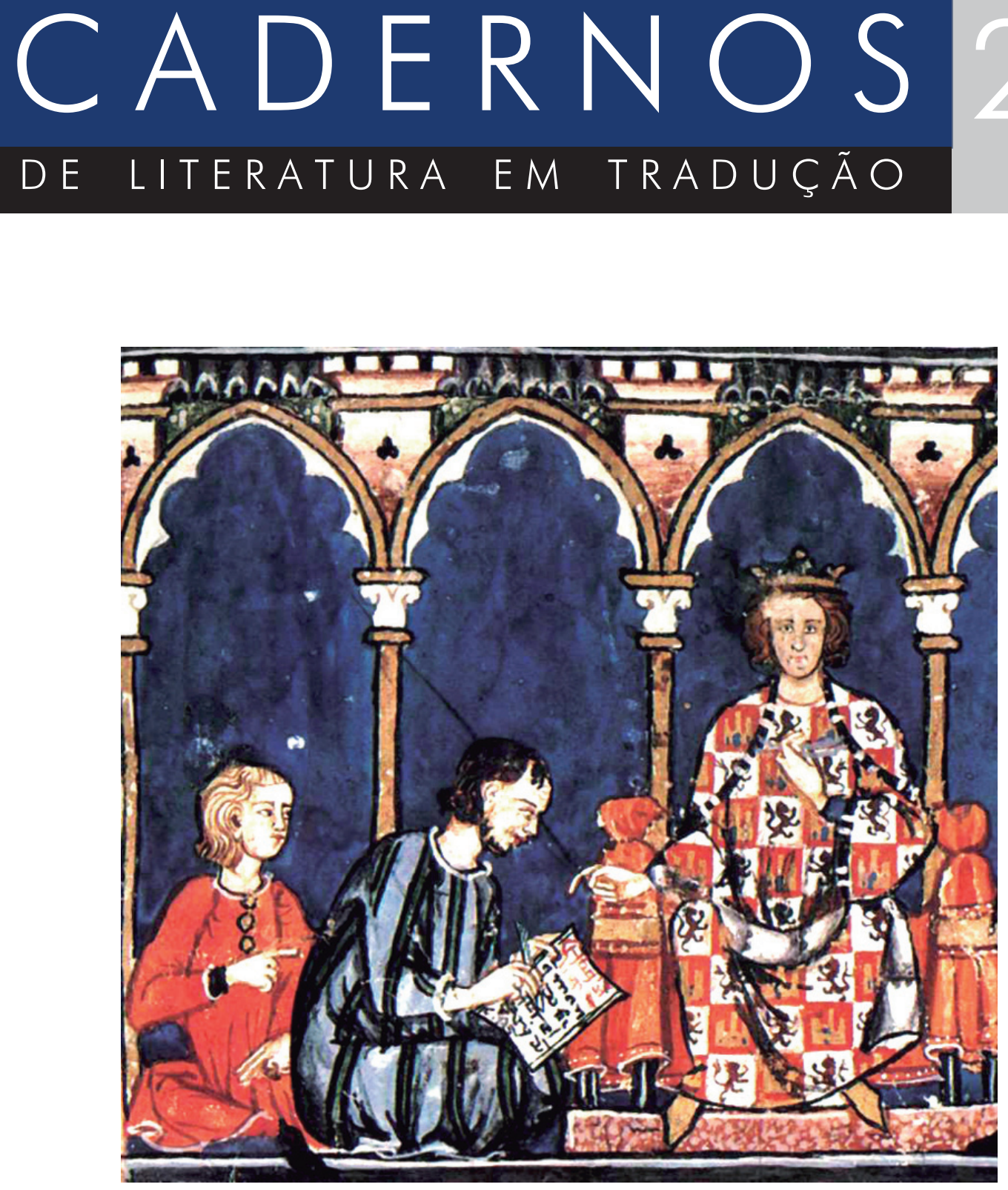

Tradutores da chamada Escola de Toledo com Afonso $X$ de Castela 


\title{
Tradução do terror em tempos de pandemia ${ }^{1}$
}

\author{
Odile Cisneros $^{2}$ \\ Mary Anne Warken ${ }^{3}$ \\ Alison Silveira Morais ${ }^{4}$
}

Resumo: Como projeto de quarentena, Mary Anne Warken e Alison Silveira Morais, alunos do Programa em Estudos da Tradução da Universidade Federal de Santa Catarina (UFSC), escolheram trabalhar com o conto "Solo" do autor chileno Aldo Astete Cuadra ("A sós" e "Alone", em suas respectivas versões), convidando Odile Cisneros da Universidade de Alberta para acompanhar e orientar esse trabalho.

Palavras-chave: Terror; Estudos da Tradução; Aldo Astete Cuadra; “Solo”; Quarentena.

"Para mim o terror é a possibilidade de explorar novos mundos, desenvolver até o extremo a imaginação, criar mundos possíveis e fazer verossímil o que não existe", comenta o escritor Aldo Astete Cuadra em entrevista a Mary Anne Warken, tradutora para o português do conto aqui apresentado conjuntamente na tradução inglesa de Alison Silveira

1 O presente trabalho foi realizado com apoio da Coordenação de Aperfeiçoamento de Pessoal de Nível Superior - Brasil (CAPES) - Código de Financiamento 001.

2 Odile Cisneros é professora Associada do Departamento de Línguas Modernas e Estudos Culturais da Universidade de Alberta, Canadá. Especialista em tradução literária, literatura de vanguarda latino-americana, mexicana e ecocrítica. Em 2019-2020 atuou como professora visitante no PPGET na UFSC.

3 Mary Anne Warken é tradutora e doutoranda no Programa em Estudos da Tradução da UFSC com bolsa CAPES. Estudiosa da Literatura Chilena e do castelhano chileno, pesquisa atualmente a obra de Nicanor Parra.

4 Alison Silveira Morais é escritor, tradutor e ilustrador, atualmente é bolsista CAPES, mestrando em Estudos da Tradução da UFSC. Sua atual pesquisa é sobre a Literatura mística medieval, possui contos publicados em antologias do gênero terror e horror desde 2016. 
Morais. Como projeto de quarentena, Mary Anne e Alison, ambos alunos do Programa em Estudos da Tradução da Universidade Federal de Santa Catarina (PGET/UFSC), escolheram trabalhar com o conto "Solo" ("A sós" e "Alone", em suas respectivas versões), e me convidaram para acompanhar e orientar esse trabalho. Nessa empreitada, ambos tradutores exploraram os desafios linguísticos e literários das narrativas de terror em que os autores criam, como aponta Astete Cuadra, realidades novas e inéditas. Considerando que a pandemia mundial de 2020, durante a qual os tradutores desenvolveram esse trabalho, é justamente uma situação sem precedentes, me pareceu que eles fizeram a escolha certa. $\mathrm{O}$ conto é de 2018 (publicado na coleção Pródromo, que teve uma segunda edição em 2019), mas a atmosfera inquietante em que se situa, um mundo cheio de ameaças, entre elas o contágio, parece ter se inspirado no momento atual. Aliás, o título da coleção é um termo médico que indica o mal-estar que precede a uma doença.

Astete Cuadra é herdeiro da importante tradição literária do terror que inclui os clássicos americanos do século XIX Edgar Allan Poe e H.P. Lovecraft. Nascido no Sul do Chile e radicado na ilha de Chiloé, Astete Cuadra aproveita as paisagens dessas regiões em sua obra. "O Sul do Chile é mágico, tem condições únicas desde o clima e a paisagem”, observa, e acrescenta, "Esse sem dúvida é um dos meus referentes enquanto a dar visibilidade para o Sul, a aventura, o desconhecido, o estranho, o macabro, a escuridão, a inclemência climática." Com esse pano de fundo, Astete Cuadra desenvolve o que ele chama de uma "narrativa del borde", categoria ampla onde podem caber tanto contos de terror, ficção científica, mitos, lendas e até comics (o escritor também já publicou nesse gênero). A característica comum nesses variados gêneros seria o componente ominoso, desagradável, transgressor, escuro e pós-humano que para o escritor chileno caracteriza nossos tempos.

"Solo" reúne todos esses elementos. Abandonado pelos pais em condições precárias, um jovem se enfrenta sozinho aos perigos de um mundo hostil e pós-apocalíptico (possivelmente resultado de uma catástrofe não mencionada) numa tentativa desesperada de sobrevivência. O rapaz empreende uma viagem que o leva do interior da casa de família abandonada até o mar. Ao longo dessa tentativa de fuga, a narrativa cria uma sensação de desassossego que vai em aumento até atingir um desenlace arrepiante.

Para o tradutor, o texto apresenta não apenas os desafios habituais da linguagem literária, mas em particular dos detalhes precisos que contribuem para a evocação de tal atmosfera de terror. Entre esses detalhes estão os espaços interiores e exteriores, por exemplo os jogos de luz e sombra criados pelas janelas de uma casa ou pelos reflexos do sol no mar, trechos que apresentavam desafios e onde ambos tradutores evocam tais pormenores do original com sucesso. Outras caraterísticas importantes são as paisagens e as condições meteorológicas. Há no original, por exemplo, repetidas referências ao vento que são expressadas de diferentes maneiras: "El viento estremecía los ventanales de la sala"; "Las ráfagas de viento que se colaban em la habitación"; e "un dia [...] de lluvia copiosa y viento huracanado". Ambos os tradutores atenderam cuidadosamente às repetições de "viento", atingindo, ao mesmo tempo, as variações do original: "O vento sacudia os janelões da sala"; "As rajadas 
de vento entravam pela habitação"; e "um dia de muita chuva e ventania,"; "The wind shook the large living room windows"; e "The gusts of wind swept through the room," "on a day [...] with a rainstorm and strong winds". Ambas as versões também conseguem reproduzir com destreza o ritmo narrativo de uma fuga desesperada, mas fútil e de um final inesperado e chocante. No seguinte trecho, por exemplo, o ritmo pontuado pelos verbos em pretérito, todas palavras oxítonas, e sua colocação precisa na sequência da frase se mantêm perfeitamente em português, enquanto o inglês, para gerar um ritmo semelhante, alterna monossílabos com verbos em pretérito com duas sílabas:

Al salir, rodeó la casa con precaución y miró desde el portón a una calle despejada de contagiados. Algunos cuerpos inertes, otros en descomposición yacían sobre el pavimento. Rogó para que ninguno de ellos fuera uno de sus padres. Luego decidió que correr por el centro de la calle, lo más alejado posible de las edificaciones, era lo más sensato bajo estas condiciones.

Ao sair, deu uma volta no entorno da casa por cautela e olhou desde o portão para uma rua livre de contagiados. Alguns corpos inertes, outros em decomposição, repousavam sobre o chão. Implorou para que nenhum deles fosse um dos seus pais. Logo decidiu correr pelo centro da rua, mantendo-se o mais longe possível das construções.

As he left, he carefully walked around the house and looked out past the gate at a street free of the infected. There, a few lifeless bodies lay, some of them in a state of decomposition strewn about on the sidewalks. He prayed that none of them were his parents. He decided then that running down in the middle of the street, as far away from the buildings as possible, was the most reasonable thing to do in that situation.

Além desses detalhes, as notas de ambos os tradutores comentam ainda outros problemas de tradução e suas soluções.

A tradução se desenvolveu a "seis mãos", uma experiência interessante em que os jovens tradutores e eu como orientadora lemos todas as versões e comentamos. Nessa colaboração, cada um contribuiu com diferentes conhecimentos contextuais e linguísticos. Dessa forma, não apenas o cotejo da tradução com o original, mas também a leitura da tradução do outro por parte dos próprios tradutores enriqueceu cada uma das versões. Esperamos que esse modelo de tradução coletiva seja tão sugestivo, quanto a leitura do conto prazerosa. 


\section{Ilustração de Alison Silveira Morais}

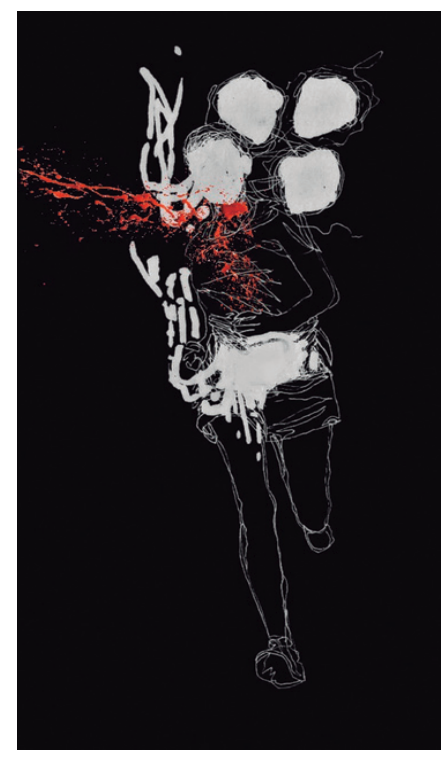

\section{SOLO}

Aldo Astete Cuadra

Aún no regresaba. Su padre había aprovechado la intensa lluvia para salir a conseguir alimentos. La urgencia y el hambre le habían forzado a dejar solo a su hijo en casa.

El viento estremecía los ventanales de la sala que aún quedaban intactos. Era el lugar más luminoso de la casa, el único sitio en donde Gonzalo aún sentía un poco de seguridad. Los marcos estaban tapiados de tal forma que, entre las tablas había espacios que filtraban la tenue luz del día invernal y permitían mirar hacia el antejardín.

Habían transcurrido seis horas desde que su padre se marchara prometiendo regresar cuanto antes. «No más allá de una hora» dijo y se fue, pese a los intentos resignados de su hijo por retenerlo. Se había quedado solo, hambriento y asustado.

Las ráfagas de viento que se colaban en la habitación actuaban como mensajes de desamparo y Gonzalo presentía que su papá no regresaría. Esto ya lo había sufrido con su madre, hacía unas semanas, en un día igual a éste, de lluvia copiosa y viento huracanado. Ella se había marchado pues no soportó el encierro de meses, volviéndose loca con la 
restricción de alimentos. Desvariaba constantemente y actuaba con inusitada violencia cada vez que sufría los punzantes retorcijones en el estómago. Es por aquella razón que la dejaron partir sin mayores aprensiones, pues ella se había convertido en un peligro latente.

En uno de aquellos arranques feroces y voraces su madre reventó el candado de la despensa y comió desesperadamente gran parte de las reservas. Su padre reaccionó para evitar que ella continuara con su demencial festín, pidiéndole que terminara de una vez por todas, que pensara en su hijo, que sólo podrían sobrevivir si mantenían el racionamiento como lo habían hecho hasta ahora. Sin embargo, obtuvo por respuesta una inesperada y feroz golpiza con el fierro que antes utilizara ella para ingresar a la reserva. Al día siguiente se marchó diciéndoles que regresaría con mucha comida, que ella sabía muy bien donde conseguirla y que la lluvia le permitiría ir y volver con todo lo necesario para cocinar una cena como nunca antes la habían tenido en casa. Estaba desequilibrada, era un peligro para ambos.

Su partida los sumió en una gran depresión, pero no intentaron retenerla, sabían que no regresaría, que no estaba en condiciones para hacer lo correcto, de hecho cada día que pasaba se iba pareciendo más a los contagiados. Ahora su padre era el que se marchaba para no volver.

La caída del atardecer confirmaba los oscuros pensamientos del niño que aguardaba acurrucado con una manta detrás del sofá, intentando escudriñar las sombras a través de las tablas en las ventanas. Un dolor agudo en el estómago le provocó un desmayo y luego un profundo sueño similar a la animación suspendida. Ya avanzada la noche un fuerte estruendo lo despertó e instintivamente llamó a su padre, pensando que había regresado y se encontraba durmiendo, sin embargo, nadie respondió. Entonces supo que ya no quedaban esperanzas.

A la mañana siguiente y luego de una noche tormentosa, entre destellos de relámpagos y sollozos, se prometió huir a los bosques, sabía, por los comentarios de su padre, que ahí habrían posibilidades de sobrevivir.

Lo visualizaba en su mente. Bajaría a la playa para salir del área urbana y llegar hasta los bosques en búsqueda de tallos y frutos silvestres y luego de encontrar un escondite podría regresar a la playa a mariscar. Si tenía suerte tal vez encontraría ayuda en alguna de las comunidades que, supuestamente, se habían formado y establecido en los bosques antes del toque de queda, cuando los más visionarios previeron lo que ocurriría después, una vez el contagio se esparciera por toda la Isla.

Que continuara lloviendo con fuerza era el mejor escenario al que se podía ver enfrentado. La lluvia amparaba a los no contagiados, protegiéndolos de los rabiosos que se ocultaban al alero de las techumbres en ruinas de un pueblo fantasma.

Salió de casa portando una mochila con afilados cuchillos, fósforos, velas y calzado de repuesto. En sus manos blandía un astil de hacha con el que su padre se había deshecho de un par de contagiados que habían logrado saltar el cerco quebrando algunos ventanales de la sala. 
Al salir, rodeó la casa con precaución y miró desde el portón a una calle despejada de contagiados. Algunos cuerpos inertes, otros en descomposición yacían sobre el pavimento. Rogó para que ninguno de ellos fuera uno de sus padres. Luego decidió que correr por el centro de la calle, lo más alejado posible de las edificaciones, era lo más sensato bajo estas condiciones. Pudo sentir murmullos que fueron in crescendo hasta transformarse en gritos destemplados, bestiales, guturales que salían de las bocas abiertas de las casas en ruinas.

Al llegar a la costanera las calles le parecieron amplias y alejadas de las viviendas, pero aun así decidió bajar a la orilla del mar que lo resguardaría de las miradas y se transformaría en su última escapatoria. Entrar al mar era una opción no tan descabellada como huir corriendo. Los bosques y campos estaban a unos kilómetros por la playa, y si la lluvia continuaba en su intensidad tendría posibilidades de llegar y tener oportunidades.

Sin embargo, en contra de sus deseos, un arcoíris despuntó en horizonte, iluminando la mañana, despejando el día paulatinamente. Debió acelerar su paso, de lo contrario estaría perdido.

De pronto, el sol alumbró irradiando la superficie del mar, y Gonzalo enceguecido creyó ver una lancha de pequeñas dimensiones que navegaba con lentitud en su dirección; no obstante, aún se encontraba a una buena distancia, le era imposible nadar, pues apenas su padre le había enseñado algo en los fríos veranos australes.

Se encontraba recordando cuando sintió a la distancia, justo detrás de él, una horda de infectados. Desesperado, corrió por la playa para acortar distancias con la embarcación, dejó atrás su mochila y se lanzó al agua con el astil como flotador.

Con las manos firmemente asidas al astil, llorando de terror y pataleando sin descanso fue acercándose a la lancha que, al parecer, había disminuido aún más su lenta marcha. Gonzalo pensaba que sería su salvación. Sobre la cubierta vio a un hombre sonriente, cuyos dientes contrastaban con una barba rojísima.

Un salvavidas rebotó cerca de él, lo cogió y fue remolcado lentamente hasta al bote, el hombre acercándose sin perder la sonrisa le habló.

- Te has salvado niño y me has salvado a mí - riéndose horriblemente.

Gonzalo al borde del colapso, se arrastró por la cubierta que estaba asquerosa, y comprendió que sería mejor desfallecer, al ver unos diez cráneos que colgaban al costado de la cabina.

El hombre tomó la cabeza del niño tirando de su pelo y cortó su garganta e inmediatamente acercó un pequeño recipiente que se llenó con sangre. Enseguida, cogió un lavatorio, y sacó el anterior en que ya se rebalsaba de sangre para dar un largo y tibio sorbo. Luego pasó su manga por la boca para limpiar los restos que se adherían al bigote y barbas. Acto seguido miró al cielo y agradeció.

- Gracias Señor por proveer los alimentos a tu hijo. Siento tu lealtad. Esta noche comeré y beberé en tu honor y agradeceré la protección que en todo momento me has brindado.

Al verificar que ya no manaba más sangre, desnudó al niño y fue destazándolo de acuerdo a las costumbres del matarife. 


\section{A sós}

\section{Tradução de Mary Anne Warken}

Ainda não tinha regressado. Seu pai tinha aproveitado a chuva intensa para buscar alimentos. A urgência e a fome tinham exigido que deixasse seu filho sozinho em casa.

O vento sacudia os janelões da sala que ainda estavam intactos. Era o lugar mais iluminado da casa e o único local onde Gonzalo ainda sentia um pouco de segurança. Entre os marcos da janela, havia frestas que filtravam a tênue luz do dia invernal e permitiam ver o jardim da frente.

Passaram seis horas desde que seu pai tinha partido com a promessa de voltar o quanto antes. "Não mais de uma hora", disse, saindo apesar das tentativas inúteis do filho de reter o pai. Acabou ficando a sós, faminto e assustado. As rajadas de vento entravam pela habitação como mensagens de desamparo, e Gonzalo pressentia que seu pai não voltaria.

Ele já tinha passado por isso antes com a mãe, fazia algumas semanas, em um dia de muita chuva e ventania, parecido com este. Sua mãe tinha partido pois não aguentou a clausura de meses e ficou louca com a restrição de alimentos. Alucinava constantemente e agia com inusitada violência cada vez que sentia os embrulhos no estômago. Ela tinha se convertido em um perigo latente, e por essa razão a deixaram ir embora.

Em um daqueles surtos ferozes e vorazes, a mãe arrebentou o cadeado da despensa e comeu desesperadamente uma grande parte das reservas. Seu pai reagiu para evitar que ela continuasse com seu insano banquete, implorando que acabasse com aquilo de uma vez por todas e que pensasse no filho, pois só poderiam sobreviver se mantivessem o racionamento como tinham feito até agora. No entanto, como resposta ele recebeu uma inesperada pancada com uma barra de ferro que antes ela tinha usado para acessar a despensa. No dia seguinte, ela partiu dizendo que voltaria com muita comida, a qual ela sabia muito bem onde conseguir e que a chuva lhe permitiria ir e voltar com tudo o que fosse necessário para cozinhar um jantar como jamais haviam tido em casa. Estava desvairada e era um perigo para ambos.

A partida da mãe fez pai e filho mergulharem em uma profunda depressão, mas não tentaram retê-la. Sabiam que não voltaria, que não tinha condições de fazer o correto e que, de fato, a cada dia que passava, mais ela se assemelhava aos contagiados. Agora seu pai era quem ia embora para não voltar mais.

A chegada do fim da tarde confirmava os obscuros pensamentos do menino que aguardava atrás do sofá encolhido e enrolado em uma manta, tentando examinar as sombras através das tábuas das janelas. Uma dor aguda no estômago lhe fez desmaiar e entrar em um sono profundo similar a uma animação suspensa. Já avançada a noite, um 
forte estrondo o despertou e instintivamente ele chamou seu pai, pensando que tinha voltado e se encontrava dormindo. No entanto, ninguém respondeu. Então soube que já não restavam esperanças.

$\mathrm{Na}$ manhã seguinte, após uma noite atormentada entre soluços de choro e clarões de relâmpagos, prometeu-se fugir e ir até os bosques. Sabia, pelos comentários do seu pai, que ali teria condições de sobreviver.

Projetava na sua cabeça: desceria até a praia para sair da área urbana e chegar aos bosques buscando plantas e frutos silvestres, e depois que encontrasse um esconderijo poderia voltar à praia para mariscar. Se tivesse sorte, encontraria ajuda em alguma das comunidades que, supostamente, tinham se estabelecido nos bosques antes do toque de queda quando os mais visionários previram o que ocorreria depois que o contágio se espalhasse por toda a Ilha.

Que continuasse chovendo com força era o melhor cenário que podia ter enfrentado. A chuva amparava aos não contagiados, protegendo-os dos raivosos que se escondiam ao amparo dos telhados em ruínas daquela cidadezinha fantasma.

Saiu de casa com uma mochila contendo facas afiadas, fósforos, velas e um par de sapatos para trocar, caso fosse necessário. Nas suas mãos, erguia um longo cabo de machado com o qual seu pai tinha se desvencilhado de um par de contagiados que tinham conseguido pular a cerca e quebrar alguns janelões da sala.

Ao sair, deu uma volta no entorno da casa por cautela e olhou desde o portão para uma rua livre de contagiados. Alguns corpos inertes, outros em decomposição, repousavam sobre o chão. Implorou para que nenhum deles fosse um dos seus pais. Logo decidiu correr pelo centro da rua, mantendo-se o mais longe possível das construções. Era o mais sensato, considerando as circunstâncias. Ao longe ouviu murmúrios que foram aumentando até se tornarem gritos descontrolados, monstruosos, guturais que saíam das bocas abertas das casas em ruínas.

Próximo à orla, as ruas lhe pareceram amplas e afastadas das casas, mas ainda assim decidiu descer até a praia onde estaria a salvo dos olhares e teria uma última chance de escapar. Entrar no mar era uma opção não tão descabida quanto fugir correndo. O bosque e o campo estavam a uns quilômetros pela praia e, se a chuva continuasse naquela intensidade, teria possibilidades de chegar até algum deles.

No entanto, ao contrário dos seus desejos, um arco-íris surgiu no horizonte, iluminando a manhã e abrindo o dia paulatinamente. Se não acelerasse o passo, estaria perdido.

De repente, o sol iluminou irradiando a superfície do mar, e Gonzalo, cego pela luz, pensou ver uma lancha de pequenas dimensões que navegava com lentidão na sua direção; porém, estava ainda muito distante e ele não tinha condições de nadar, já que seu pai tinha lhe ensinado muito pouco de natação nos frios verões austrais.

Estava distraído com seus pensamentos e recordações quando percebeu ao longe, justo atrás dele, um bando de infectados. Desesperado, correu pela praia para diminuir 
a distância entre ele e a embarcação. Abandonou sua mochila e atirou-se na água com o cabo do machado como boia.

Com as mãos agarradas fortemente na madeira, chorando de terror e batendo pernas sem descanso, foi se aproximando da lancha que, ao que parecia, tinha diminuído ainda mais sua marcha lenta. Gonzalo pensava que seria sua salvação. Sobre a coberta, viu um homem sorrindo, cujos dentes contrastavam com uma barba muito vermelha.

Uma boia salva-vidas o alcançou. O menino a agarrou e foi se aproximando devagar até o bote. $\mathrm{O}$ homem se aproximou sem perder o sorriso e disse:

- Você se salvou, menino, e me salvou também - rindo horripilantemente.

Gonzalo, à beira de um colapso, rastejou pelo chão do barco, que estava um nojo, e entendeu que teria sido melhor desmaiar quando viu os dez crânios que estavam pendurados nas laterais da cabine.

O homem alcançou a cabeça do menino, puxando-a pelos cabelos, e cortou sua garganta, aproximando imediatamente um pequeno pote que se encheu de sangue. Depois, substituindo o pote transbordante pela bacia do lava-mãos, tomou um longo gole de sangue. Então, passou a manga da camisa pela boca para limpar os restos que estavam grudados no bigode e barba. Olhou para o céu e agradeceu.

- Graças a vós, Senhor, por prover alimento para vosso filho. Posso sentir vossa lealdade. Esta noite comerei e beberei em vossa homenagem e agradecerei a proteção que em todo momento me brindastes.

Depois de conferir que não jorrava mais sangue, despiu o menino e foi esquartejando seu corpo com a habilidade de um açougueiro. 


\section{Nota da tradutora Mary Anne Warken}

A tradução colaborativa do castelhano para o português brasileiro que apresentamos foi realizada a seis mãos. Alison Silveira Morais, ilustrador, que ademais de tradutor é também autor de contos de terror publicados no Brasil, participou neste projeto oferecendo a leitura e o olhar de quem conhece o gênero intimamente. A coordenação da Professora Odile Cisneros, que, domina os idiomas castelhano, inglês e português, nos ajudou ver o trabalho como um todo e em cada detalhe. Nosso diálogo e trabalho em equipe provocou novas leituras e com essa troca foi possível que encontrássemos as escolhas que apresentamos nesta publicação.

Nossa conversa foi desenhando um projeto de tradução compartilhado, nos estimulou a intervir no texto quando foi necessário, tendo sempre como objetivo buscar uma articulação no idioma português e trazer o suspense que líamos na narrativa de terror para nossa tradução. Além disso, queríamos que a leitura em português trouxesse os cenários que o autor descreveu. O processo se desenvolveu de forma harmoniosa, e, em virtude da pandemia, sempre com encontros virtuais e utilizando ferramentas online para a troca de ideias e observações.

A tradução para o inglês ajudou pensar a tradução para o português, e interferiu de forma positiva. Ter acesso a outra leitura, e outra tradução do mesmo texto, para outro idioma, transformou-se em ferramenta de reflexão para a tradução ao português.

Sobre a tradução de textos literários chilenos, deve-se considerar, que de forma geral, naquelas literaturas em que escritoras e escritores inserem falas de personagens chilenos, ou narrativas com idiomatismos, podem ser encontrados na estrutura do texto aspectos linguísticos desse castelhano que merecem maior atenção na tradução ao português. Porém, no conto que traduzimos, pode-se dizer que características mais marcadas dessa variedade não foram encontradas. As dificuldades que tivemos não decorrem de particularidades da variedade linguística chilena. A única voz de personagem dentro da narração onisciente é a seguinte "Te has salvado niño y me has salvado a $m \hat{\imath}$ ". Fala que se expressa de forma mais neutral e o uso da flexão do "tú" ocorre de forma padrão normativa.

Também não encontramos inserção de nomes em mapudungum ou quéchua, línguas indígenas faladas no território chileno e normalmente presentes na toponímia, fauna e flora chilenas. Os cenários descritos podem remeter a um território que não necessariamente seja chileno, apesar de que pequenos fragmentos lembram características do sul do Chile "Iluvia copiosa y viento buracanado", "invierno austral", um clima inclemente, elemento sumamente importante no ambiente 
inquietante que o conto evoca. Estão neste texto traduzido por nós, possíveis marcas do gênero de terror herdeiro da poesia dos lares ${ }^{5}$, chamado por Aldo Astete Cuadra: Terror Lárico. O cenário externo se relaciona com detalhes na descrição do ambiente e um estado de ânimo particular: "Las ráfagas de viento que se colaban en la habitación actuaban como mensajes de desamparo".

Sobre as escolhas tradutórias, sempre compartilhadas e conversadas com Alison e com Odile, nos deparamos com diferentes possibilidades desde o título do conto: "Solo" em castelhano e "A sós" e "Alone" nas nossas traduções. Para essas decisões finais foram pensadas e analisadas outras possibilidades, no título, por exemplo, em detrimento de "Sozinho" preferimos "A sós", essa escolha abre o estado de solidão não apenas para um personagem masculino, (menino, pai, assassino), mas também para todos outros personagens: mãe, infectados, todos eles em situação de solidão, ou seja " $A$ sós".

Em alguns momentos optamos pelo diminutivo para trazer ao texto imagens que líamos no texto de referência, é o caso do fragmento que selecionei logo abaixo:

La lluvia amparaba a los no contagiados, protegiéndolos de los rabiosos que se ocultaban al alero de las techumbres en ruinas de un pueblo fantasma. / A chuva amparava aos não contagiados, os protegendo dos raivosos que se escondiam ao amparo dos telhados em ruínas daquela cidadezinha fantasma.

A expressão "animación suspendida" utilizada no conto, fez com que consultássemos Aldo, para ter certeza do significado dela dentro da narrativa. $\mathrm{Na}$ tradução ao português mantivemos o "animação suspensa", uma expressão que remete a uma breve interrupção da vida, expressão bastante presente em literatura de ficção.

Em outros casos, a tradução de uma só palavra no texto de referência foi composta por mais palavras, como é o caso de "costanera", que na nossa tradução ao português ficou "Avenida à beira-mar".

5 N.T. A poesia dos lares está associada aos projetos poéticos dos poetas chilenos Floridor Pérez (1937-2019) e Jorge Teiller (1935-1996). Jorge Teiller, referência reconhecida por Aldo Astete Cuadra, no artigo "Los poetas de los lares: nueva visión de la realidad en la poesía chilena", publicado em 1965, discorre sobre elementos compositivos da poesia dos lares, uma poesia que pode ser lida integrada ao seu entorno, a paisagem e que destaca a relação do homem com o mundo que o rodeia. Dessa forma, o "lárico" pode ser visto como um movimento literário que coloca luzes na comunicação e relações dos sujeitos com a materialidade do mundo e a própria natureza. Cabe lembrar que o autor resgata lendas e mitos do sul do Chile, região com forte presença da cultura mapuche e onde está localizado o arquipélago de Chiloé, conhecido por suas lendas de bruxas, mitos e tradições próprias. 
Foram consultados os dicionários da Real Academia Española em sua versão online e o Diccionario de uso del español de Chile publicado pela Academia Cbilena de la lengua. Além disso, contamos com a oportunidade de dialogar com o autor do conto, que sempre esteve disponível e respondeu as dúvidas que surgiram durante o processo de tradução de sua obra. Contar com o conhecimento do autor e do tradutor Alison, especializados no gênero terror, tornou o trabalho de tradução colaborativo bastante rico, e a coordenação de Odile, que lia o texto nos três idiomas, foi uma experiência muito enriquecedora. Sem dúvida essa oportunidade fez com que através desse diálogo, pudéssemos modificar alguns elementos tendo como horizonte oferecer uma maior aproximação com as imagens contidas na narrativa de terror de Aldo Astete Cuadra. 


\section{ALONE}

\section{Traducão de Alison Silveira Morais}

He wasn't back yet. His father had taken advantage of the heavy rain to go out in search of some food. Hunger and the urgency of the situation had forced him to leave his son alone at home.

The wind shook the large living room windows, which remained intact. It was the brightest place in the house, the only place where Gonzalo still felt some sense of security. The window frames were set in such a way that there were cracks, which let the faint light of that winter day in, allowing a view of front yard.

Six hours had passed since his father had left, promising to return as soon as possible. "Not more than an hour," he had said before leaving, despite the futile attempts of his son to hold him back. He was alone, hungry, and frightened.

The gusts of wind swept through the room like a message of helplessness, and Gonzalo felt that his father would not return. He had suffered through the same thing a few weeks earlier with his mother, on a day like this, with a rainstorm and strong winds. She had left, unable to bear the endless months of confinement anymore, and having gone mad because of the food rationing. She hallucinated constantly and behaved in an unusually violent way whenever she felt those sharp stomach pains. For this reason, they let her go without hesitation, since she had become a growing threat.

In one of those furious and ravenous outbreaks, his mother had broken the padlock of the kitchen pantry and desperately eaten most of their food supplies. His father had tried to stop her insane feasting, asking her to put an end to it once and for all, trying to make her think of their son, and warning they would only survive if they kept rationing the food, as they had done up until that moment. In response, he received an unexpected beating with the metal rod she had used to force the pantry lock. She left the next day, saying that she would return with lots of food, that she knew very well where she could get it. The rain would allow her to go and come back with everything she needed to cook a dinner like they had never seen before. She was mentally unstable and had become a threat to both of them.

Her departure plunged them into a deep depression, but they did not try to hold her back. They knew she would not return anymore, that she was not capable of doing the right thing - in fact, with each passing day, she looked more and more like one of the infected ones. Now, it was his father who was leaving never to return.

Twilight confirmed the boy's dark expectations. He was waiting, wrapped up in a blanket behind the sofa, trying to peer out into the shadows forming through the window 
frames. A sharp pain in his stomach made him pass out and he went into a deep sleep, into a state similar to suspended animation. Later that night, a loud bang woke him up, and instinctively he called out for his father, thinking he might have returned and would be sleeping, but there was no answer. He realized then there was no hope left.

The following morning, after a night of lightning flashes and sobs, the boy promised himself he would flee to the woods. He knew, from his father's comments, that there he could still manage to survive.

He visualized everything in his mind. He would first go down to the beach to leave the urban area behind and reach the woods in search of stems and fruits. Then he would find a place where he could hide and return to, and finally, he would go back to the beach to gather shellfish. If he was lucky, he might find help in the communities that had supposedly formed in the woods prior to the lockdown, when the greatest visionaries predicted what would happen once the infection had spread all over the Island.

That continuous and heavy rain was the best scenario he could face. The downpour protected the non-infected from those stricken by rabies, who hid under the dilapidated roofs of that ghost town.

He left the house carrying a backpack containing a sharp knife, matches, candles, and an extra pair of shoes. He wielded an axe handle, which his father had used to rid himself of a couple of the infected who managed to jump over the fence and break the living room windows.

As he left, he carefully walked around the house and looked out past the gate at a street free of the infected. There, a few lifeless bodies lay, some of them in a state of decomposition strewn about on the sidewalks. He prayed that none of them were his parents. He decided then that running down in the middle of the street, as far away from the buildings as possible, was the most reasonable thing to do in that situation. He could hear the din growing louder and louder until it turned into wild screams, inhuman and guttural growling coming from open mouths hidden among the ruins.

When he arrived at the coastline, the streets seemed to be wider and far from the houses, but he still decided to keep going towards the seashore, something that would prevent him from drawing attention and give him his last chance. To dive into the sea didn't seem a worse idea than to run away. The woods and the fields were just a few kilometers from the beach, and if went on raining with the same intensity, he might arrive there and have a chance.

However, and contradicting his wishes, a rainbow appeared on the horizon, illuminating the morning, gradually clearing up the sky. He had to hurry, otherwise, he would be done for. All of a sudden, the sun's rays hit the surface of the ocean, and Gonzalo was instantly blinded by the light, but he saw a small boat sailing slowly towards him. Although, it was still far away, he was unable to swim towards it because, in the cold northern summers, his father had barely taught him how. 
He was reminiscing about his past, when he felt an infected horde right behind him. Horrified, he ran along the beach to get closer to the boat. He left his backpack behind and dove into the sea, using his ax handle as a floater.

Holding on to the handle with all his might, crying in terror, and desperately kicking his legs, he approached the boat, which seemed to be slowing down gradually. Gonzalo thought that this was his salvation. On the deck he saw a smiling man, whose teeth contrasted with a very red beard.

A life-saver floated in the water next him, so he grabbed it and was towed to the boat. As he was getting closer, the man kept smiling and said to him:

- You have been saved, boy, and you saved me too - laughing hideously.

On the verge of collapse, Gonzalo crawled across the revolting deck and realized that it would have been better to pass out when he noticed ten skulls hanging by the side of the cabin.

The man grabbed the boy by the hair and slashed his throat, bringing a small container close to it, which soon filled up with blood. He then reached for a hand washing basin, removed the overflowing container and took a long sip of the warm blood. He wiped off his mouth and beard with his shirt sleeve, then looked up to the sky giving thanks:

- Thank you, Lord, for providing food for your son! I feel your loyalty towards me. This night I shall eat and drink in your honor and appreciate your sheltering grace at all times towards me.

When he noticed the blood had stopped flowing, he removed the boy's clothes and cut him into pieces, like a butcher would do.

\section{Nota do tradutor Alison Silveira Morais}

Minha motivação para debruçar sobre essa obra fantástica de terror e horror foi através do convite de Mary Anne Warken, que já conhecia o autor e sua obra. Tendo concluído a leitura pela primeira vez, tive certeza absoluta que adoraria trabalhar nela. Aprecio enormemente os gêneros literários de terror e horror, e o tom e o ritmo da história me comoveram, também pelas evidentes referências com o momento de pandemia que vivemos. Algo que chama atenção no conto é como o autor deixa a responsabilidade para o leitor de interpretar a situação e também os demais personagens. Temos o ponto de vista do menino Gonzalo, mas não conhecemos seu pai, sua mãe, e também não podemos afirmar por qual tipo de pandemia eles passaram, desde quando e detalhes sobre seus efeitos nos "infectados" (mesmo fazendo algumas alusões a clássica figura dos zumbis).

Possuo bastante familiaridade com o idioma espanhol, entretanto, costumo trabalhar nos caminhos português x inglês e vice-versa, o que foi um aprendizado constante, tirando dúvidas sobre contexto e o próprio idioma espanhol com Mary Anne Warken e recebendo muitos feedbacks positivos da Profa. Dra. Odile Cisneros. 
Essa grande pesquisa para a construção dessa tradução foi um divisor de águas, pois foi também enriquecedor aprender mais sobre o próprio idioma inglês. Alguns exemplos específicos se mostraram especialmente desafiadores devido ao caráter polissêmico de algumas palavras traduzidas do espanhol, como por exemplo, "la costanera" e "orilla del mar", onde tanto no inglês como no português, giram em torno de um mesmo termo "litoral" ou em inglês "coastline" e "shore", que são utilizadas como sinônimas de acordo com dicionários como Oxford English Dictionary, Merriam-Webster e Thesaurus.

Outros momentos interessantes foram as palavras "mariscar" que vemos como um verbo, mas que tanto em português quanto em inglês necessitam de um verbo que antecede o substantivo: o animal em si "marisco", sendo catar marisco, juntar, recolher etc., assim como no inglês que vem, geralmente, acompanhado por "gather" ou "harvest" shellfish. As palavras "techumbres", devido sua grande variedade de sinônimos e traduções (telhado, teto, forro, cobertura, etc.), tornou necessária uma análise do contexto para tomar algumas decisões. À curiosa "salvavidas", que em espanhol, com recorrência refere-se a boia salva vidas e não ao "socorrista" que em português se chama "salva-vidas", então foi adicionado o "floated in the water..." depois de "life-saver" como um recurso contextual. Essa decisão foi para evitar ambiguidades, já que a palavra "reboto" no original pode significar ricochetear, bater e saltar.

Por fim, a fala do homem no barco, após ter salvado a vida de Gonzalo, foi onde meus recentes estudos em Literatura Mística Medieval e Teologia Medieval se mostraram grandes aliados para essa tradução, devido ao tom místico de proximidade com seu deus:

\begin{tabular}{|c|c|}
\hline $\begin{array}{l}\text { - Gracias Señor por proveer los alimen- } \\
\text { tos a tu hijo. Siento tu lealtad. Esta noche } \\
\text { comeré y beberé en tu honor y agradece- } \\
\text { ré la protección que en todo momento } \\
\text { me has brindado. }\end{array}$ & $\begin{array}{l}\text { - Thank you, Lord, for providing food } \\
\text { for your son! I feel your loyalty towards } \\
\text { me. This night I shall eat and drink in } \\
\text { your honor and appreciate your shelter- } \\
\text { ing grace at all times towards me. }\end{array}$ \\
\hline
\end{tabular}

Aqui decidi substituir "proteção", que poderia ter sido uma boa tradução para o original "protección", por "sheltering grace", como forma de enfatizar a intensidade e o caráter religioso do personagem, como um preludio à justificativa para seu ato grotesco.

$\mathrm{Na}$ literatura mística medieval, a palavra de Deus se resumia em "experiência". Sendo assim, muitas vezes, a própria Bíblia ficava em segundo plano para dar lugar aos sentidos, visões, ao mistério, a proximidade com Deus, o que gerava certa liberdade para reinterpretação da religião. O místico possuía uma forma especial de conhecimento de Deus, que não vinha através das missas, nem pelas autoridades, mas com a comunicação expressa com ele, através de diálogos internos. É esse o caso dessa passagem, que dá contorno e cor a essa proximidade e também a distorção interpretativa beirando o fanatismo, que coloca como "graça acolhedora" o fato de poder degolar o menino para sobreviver em meio ao caos. 
Pensamos juntos em elaborar uma ilustração para as traduções, e foi muito importante desenvolver esse desenho após o final de todo o processo de debates, tradução e revisão. Imagino que nele é expressado, não somente traços do que poderia ser o menino correndo de seus medos - porém já fadado ao fracasso -, mas também o próprio desafio desta tradução.

A ilustração, foi feita com caneta nankin sakura Pigma Micron preta 0.3 e 0.5 em folha Canson XL Aquarela $300 \mathrm{gm}^{2}$ e arte final elaborada digitalmente no Photoshop.

\section{Referências bibliográficas}

CUADRA, Aldo Astete. Solo. Pródomo. $2^{\text {a }}$ ed. Lima: Ángeles del Papel Editores, 2019, p. 47.

CUADRA, Aldo Astete. Entrevista com o escritor chileno Aldo Astete Cuadra a partir da tradução do conto de terror "El suicidante del Moraleda" para língua portuguesa. BEZERRA, Mara. WARKEN, Mary Anne. ZILS. Elys Regina. Florianópolis: Revista Qorpus. 2019, p. 155. Disponível em: https://qorpuspget.paginas.ufsc.br/files/2019/11/ Entrevistas2 Qorpus-v9-n2 Bezerra Warken Zils.pdf Acesso em: 21 maio 2020. 